\title{
Activity of Gemifloxacin against Quinolone-Resistant Streptococcus pneumoniae Strains In Vitro and in a Mouse Pneumonia Model
}

\author{
E. Azoulay-Dupuis, ${ }^{1 *}$ J. P. Bédos, ${ }^{1}$ J. Mohler, ${ }^{1}$ P. Moine, ${ }^{1}$ C. Cherbuliez, ${ }^{2}$ G. Peytavin,${ }^{1}$ \\ B. Fantin, ${ }^{1}$ and T. Köhler ${ }^{2}$ \\ INSERM EMI-U 9933, Faculté de Médecine Xavier Bichat, Paris, France, ${ }^{1}$ and Department of \\ Microbiology and Molecular Medicine, University of Geneva, Geneva, Switzerland ${ }^{2}$
}

Received 2 June 2004/Returned for modification 26 July 2004/Accepted 9 November 2004

\begin{abstract}
Gemifloxacin is a novel fluoronaphthyridone quinolone with enhanced in vitro activity against Streptococcus pneumoniae. We investigated the activities of gemifloxacin and trovafloxacin, their abilities to select for resistance in vitro and in vivo, and their efficacies in a mouse model of acute pneumonia. Immunocompetent Swiss mice were infected with $10^{5} \mathrm{CFU}$ of a virulent, encapsulated $S$. pneumoniae strain, $\mathrm{P}-4241$, or its isogenic parC, gyr $A$, parC gyr $A$, and efflux mutant derivatives (serotype 3); and leukopenic mice were infected with $10^{7} \mathrm{CFU}$ of two poorly virulent clinical strains (serotype 11A) carrying either a parE mutation or a parC, gyrA, and parE triple mutation. The drugs were administered six times every $12 \mathrm{~h}$, starting at either 3 or $18 \mathrm{~h}$ postinfection. In vitro, gemifloxacin was the most potent agent against strains with and without acquired resistance to fluoroquinolones. While control mice died within 6 days, gemifloxacin at doses of 25 and $50 \mathrm{mg} / \mathrm{kg}$ of body weight was highly effective (survival rates, 90 to 100\%) against the wild-type strain and against mutants harboring a single mutation, corresponding to area under the time-versus-serum concentration curve at $24 \mathrm{~h}$ $\left(\mathrm{AUC}_{24}\right) / \mathrm{MIC}$ ratios of 56.5 to 113 , and provided a $40 \%$ survival rate against a mutant with a double mutation (parC and $g y r A)$. A total $\mathrm{AUC}_{24} / \mathrm{MIC}$ ratio of 28.5 was associated with poor efficacy and the emergence of resistant mutants. Trovafloxacin was as effective as gemifloxacin against mutants with single mutations but did not provide any protection against the mutant with double mutations, despite treatment with a high dose of 200 $\mathrm{mg} / \mathrm{kg}$. Gemifloxacin preferentially selected for parC mutants both in vitro and in vivo.
\end{abstract}

Community-acquired pneumonia is the most common cause of death due to infection, with Streptococcus pneumoniae remaining the leading causative pathogen $(27,28,33)$. The worldwide incidence of infections caused by pneumococci resistant to penicillin, macrolides, and other antimicrobials has increased at an alarming rate during the past two decades $(3,4)$. There is thus considerable interest in the use of alternative antimicrobials such as fluoroquinolones. Although fluoroquinolones are available, fluoroquinolones such as ciprofloxacin have limited effectiveness in this setting (7), and recently developed compounds appear to be more interesting for this purpose $(5,8,35)$.

Several studies have shown that low-level quinolone resistance in pneumococci can result from mutations in the parC gene, which codes for topoisomerase IV (30). Increased levels of resistance occur following acquisition of additional mutations in gyrA, which encodes the A subunit of type II topoisomerase (DNA gyrase) (24). The impact of these two resistance mechanisms depends on the type of molecule considered (35). Moreover, recent studies have identified an efflux mechanism as a further cause of low-level resistance in pneumococci (11, 40). Combination of this efflux mechanism with mutations on the DNA gyrase $($ gyr $A)$ or topoisomerase IV (parC) gene leads to higher levels of resistance.

Gemifloxacin (SB 265805) is a new fluoronaphthyridone quinolone with a 7-pyrrolidone substituent. This novel com-

* Corresponding author. Mailing address: INSERM EMI-U 9933, Faculté Xavier Bichat, 16, rue Henri Huchard, 75870 Paris Cedex 18, France. Phone: (33) 1448561 53. Fax: (33) 1448561 47. E-mail: eazoulay@bichat.inserm.fr. pound has been shown to have excellent in vitro activity against both gram-negative and gram-positive pathogens $(26,37,39)$ and against atypical pathogens such as Mycoplasma pneumoniae, Chlamydia pneumoniae, and Legionella pneumophila $(15,16)$. Gemifloxacin is the most potent member of the quinolone class against isolates of $S$. pneumoniae with reduced susceptibilities to ciprofloxacin (13).

The aim of this study was to evaluate the efficacy of gemifloxacin in vitro and in a mouse model of acute pneumonia caused by an $S$. pneumoniae wild-type strain and by isogenic quinolone-resistant mutants in terms of both bactericidal activity and selection of resistance in comparison with the efficacy of trovafloxacin, a trifluoronaphthyridone quinolone which demonstrated a high degree of efficacy against $S$. pneumoniae both in vitro and in a mouse pneumonia model (8).

\section{MATERIALS AND METHODS}

Drugs. The antibiotics used in this study included the fluoroquinolones gemifloxacin (SmithKline Beecham Pharmaceuticals, Brentford, United Kingdom), trovafloxacin (Pfizer Laboratories, Groton, Conn.), ciprofloxacin and moxifloxacin (Bayer Laboratories, Sens, France), sparfloxacin (Rhône-Poulenc Rorer Laboratories, Nanterre, France), and norfloxacin (Merck Sharp \& Dohme, Fontenay-sous-Bois, France). Ethidium bromide was purchased from Sigma (Saint Quentin Fallavier Cedex, France). The antibiotics were diluted in sterile water to the desired concentrations.

Bacterial strains. The strains used for the in vivo studies are shown in Table 1. S. pneumoniae P-4241 is a blood isolate (serotype 3 ) and an encapsulated strain which is virulent in a mouse model of acute pneumonia (100\% lethal dose, $3.3 \log _{10} \mathrm{CFU} / \mathrm{mouse}$ ). It is susceptible to both penicillin and quinolones (amoxicillin MIC, $0.03 \mu \mathrm{g} / \mathrm{ml}$; ciprofloxacin MIC, $1 \mu \mathrm{g} / \mathrm{ml}$ ). Isogenic gyrA and parC mutants were selected from parent strain P-4241 as reported previously (6). Strains 2500 and 2759 (serotype 11A) are poorly virulent clinical isolates carrying a single mutation in parE and mutations in gyrA, parC, and parE, respectively. 
TABLE 1. MICs and mutations in strains used for animal studies ${ }^{a}$

\begin{tabular}{|c|c|c|c|c|c|c|c|c|}
\hline \multirow{2}{*}{ Genotype [mutation(s)] } & \multirow{2}{*}{ Strain } & \multicolumn{7}{|c|}{$\operatorname{MIC}(\mu \mathrm{g} / \mathrm{ml})$} \\
\hline & & $\overline{\text { GEM }}$ & TVA & MXF & SPX & CIP & NOR & $\overline{\mathrm{EtBr}}$ \\
\hline WT ( $\operatorname{par} C$, Ser79; gyrA, Ser81) & P-4241 & 0.03 & 0.125 & 0.125 & 0.5 & 1 & 8 & 4 \\
\hline $\operatorname{parC}$ (Ser79Tyr) & $\mathrm{C} 42-\mathrm{R} 2$ & 0.06 & 0.5 & 0.125 & 0.5 & 4 & 64 & 8 \\
\hline gyrA (Ser81Tyr) & $\mathrm{Sp} 42-\mathrm{R} 1$ & 0.06 & 0.125 & 0.25 & 1 & 1 & 8 & 4 \\
\hline parC (Ser79Tyr) gyrA (Ser81Tyr) & $\mathrm{C} 42-\mathrm{Sp} 6$ & 0.5 & 8 & 4 & 16 & 32 & 128 & 8 \\
\hline Efflux mutant (ND) & N42-6R1 & 0.06 & 0.18 & ND & 0.5 & 4 & 16 & 16 \\
\hline parE (Ile460Val + Asp435Asn) & 2500 & 0.125 & 0.5 & ND & 0.5 & 16 & $>64$ & 32 \\
\hline parC (Ser79Tyr) gyrA (Ser81Tyr) parE (Ile460Val) & 2759 & 1 & 16.0 & 8 & 32 & 64 & $>64$ & 32 \\
\hline
\end{tabular}

${ }^{a}$ Abbreviations: WT, wild type; GEM, gemifloxacin; TVA, trovafloxacin; MXF, moxifloxacin; SPX, sparfloxacin; CIP, ciprofloxacin; NOR, norfloxacin; EtBr, ethidium bromide; ND, not determined.

S. pneumoniae 1427 is a laboratory susceptible strain (gemifloxacin MIC, $0.06 \mu \mathrm{g} /$ $\mathrm{ml}$ ) that was used for in vitro selection of gemifloxacin-resistant mutants since it yielded more fluoroquinolone-resistant mutants than virulent strain P-4241 did.

MIC determinations. MICs were determined by the broth microdilution method in Columbia medium supplemented with 5\% sheep blood (32).

Selection and analysis of first-step mutants resistant to gemifloxacin in vitro. Inocula of $10^{9}$ to $10^{10} \mathrm{CFU}$ of $S$. pneumoniae strain 1427 were plated on Columbia agar plates that were supplemented with 5\% sheep blood and that contained gemifloxacin at final concentrations of one-half the MIC, the MIC, and two times the MIC. Emergence of resistant colonies was monitored for $48 \mathrm{~h}$, and tests for the acquisition of mutations in the quinolone resistance-determining regions (QRDRs) of gyrA and $\operatorname{parC}$ were performed. QRDRs were amplified by PCR with primer pair VGA3 (5'-CCGTCGCATTCTTTACG) and VGA4 (5'-AGTTGCTCCATTAACCA) for gyrA and primer pair M0363 (5'-TGGGT TGAAGCCGGTTCA) and M4271 (5'-TGCTGGCAAGACCGTG) for parC (34). PCR conditions were as follows: 1 cycle of $1 \mathrm{~min}$ at $95^{\circ} \mathrm{C}$, followed by 25 cycles of $30 \mathrm{~s}$ at $95^{\circ} \mathrm{C}, 30 \mathrm{~s}$ at $50^{\circ} \mathrm{C}$, and $90 \mathrm{~s}$ at $72^{\circ} \mathrm{C}$, with a final 5 -min extension step at $72^{\circ} \mathrm{C}$. PCR fragments were purified through spin columns (Qiagen, Hilden, Germany) and directly sequenced at the sequencing facility of the University of Geneva with the primers described above and an ABI A377 automatic sequencer (Applied Biosystems, Foster City, Calif.).

Analysis of strains recovered from mice. Bacteria were recovered from homogenated lungs of treated and untreated control animals. Lung homogenates (100 $\mu l)$ were spread on Columbia agar plates supplemented with $5 \%$ sheep blood. Approximately 10 individual colonies were isolated at random after overnight culture at $37^{\circ} \mathrm{C}$, and their resistance profiles were determined. Strains for which MICs were higher than the control value were further investigated. The QRDRs were amplified and sequenced as described above.

Infection of mice with $S$. pneumoniae. Animal studies were performed in accordance with prevailing regulations regarding the care and use of laboratory animals of the European Commission (17). Swiss mice (weight, 20 to $22 \mathrm{~g}$; Iffa Credo, L'Arbresle, France) were infected by the intratracheal route with $40 \mu \mathrm{l}$ of bacterial suspension at a dose of approximately $10^{5} \mathrm{CFU}$ of virulent $S$. pneumoniae per immunocompetent mouse and $10^{7} \mathrm{CFU}$ of a poorly virulent strain per leukopenic mouse. The animals were rendered leukopenic by intraperitoneal administration of $150 \mathrm{mg}$ of cyclophosphamide/ $\mathrm{kg}$ of body weight/day for 3 days, starting 4 days before infection. This treatment reduces leukocyte counts from about 7,000 to $1,000 / \mathrm{ml}$ of blood on the day of bacterial challenge and the neutrophil counts to about $100 / \mathrm{ml}$ (5). Both a high inoculum and leukopenia were required to induce pneumonia with poorly virulent strains.

Antibiotic treatment. Therapy was initiated $18 \mathrm{~h}$ after challenge with the wild-type virulent penicillin-susceptible strain (P-4241) and with the virulent quinolone-resistant mutants (parC, gyrA, efflux, and parC gyrA mutants) and $3 \mathrm{~h}$ after challenge with the poorly virulent parE and parC gyrA parE clinical strains. Early treatment initiation was required because the immunocompromised mice infected with the poorly virulent strains developed pneumonia shortly after they received a high bacterial inoculum. Immunocompetent mice infected with virulent strains developed pneumonia later, and thus, initiation of treatment was delayed. Gemifloxacin and trovafloxacin were given as six subcutaneous (s.c.) injections at 12-h intervals at doses of $6.25,12.5,25$, and $50 \mathrm{mg} / \mathrm{kg}$ to mice challenged with the wild-type strain and the strains with single mutations. Trovafloxacin was given at doses of 100 and $200 \mathrm{mg} / \mathrm{kg}$ and gemifloxacin was given at doses of 50 and $75 \mathrm{mg} / \mathrm{kg}$ to mice challenged with the strain with the double mutation ( $\operatorname{parC}$ and gyrA). Ciprofloxacin was injected at 100 and $250 \mathrm{mg} / \mathrm{kg}$. Infected, untreated control mice received the same volume of isotonic saline. Each treatment group comprised between 12 and 16 animals. The observation period was 10 days. Death rates were recorded daily, and cumulative survival rates were compared.

Bactericidal activity in vivo. The protocol used to study bactericidal activity was the same as that used for the mouse survival studies. The total CFU counts recovered from whole-lung homogenates were determined $6 \mathrm{~h}$ after the first treatment, which was initiated $18 \mathrm{~h}$ after bacterial challenge, and $13 \mathrm{~h}$ after the second, fourth, and sixth treatments at doses of $6.25,12.5,25$, and $50 \mathrm{mg}$ of gemifloxacin per $\mathrm{kg}$. Three mice were used for each dose and time point. Mice were killed by intraperitoneal injection of sodium pentobarbital and were exsanguinated by cardiac puncture; blood was used for cultures. The lungs were removed and homogenized in $1 \mathrm{ml}$ of normal saline. One hundred microliters of whole-lung homogenate or serial 10 -fold dilutions of homogenates were plated on Columbia agar. Blood was cultured in brain heart infusion broth. After overnight culture, the colonies on the agar plates seeded with lung tissue samples were counted, and blood cultures were examined for turbidity. The results are expressed as the mean \pm standard deviation $\log _{10}$ CFU per lung and as the number of positive or negative blood cultures for groups of three mice each.

Determination of gemifloxacin concentrations in serum and lung and pharmacokinetic (PK) analysis. Antibiotics were administered as a single s.c. dose of $25 \mathrm{mg}$ of gemifloxacin or trovafloxacin per $\mathrm{kg}$ to both infected and uninfected mice. Infected mice were treated at $18 \mathrm{~h}$ postinfection. Serum and lung samples were collected from groups of six mice each at $0.25,0.5,1,2,4,6,8,12$, and $24 \mathrm{~h}$ after drug administration. All samples were frozen at $-20^{\circ} \mathrm{C}$ and protected from light to avoid gemifloxacin degradation during analysis. Lung tissue samples were crushed in liquid nitrogen by magnetized crushing (Spex; Fisher Bioblock, Illkirch, France). Preparation of the calibration standard started with a standard stock solution. Approximately $14 \mathrm{mg}$ of gemifloxacin (LB20304a) was placed into a labeled, volumetric flask and dissolved with methanol at a final concentration of $2.5 \mathrm{mg} / \mathrm{ml}$. The final concentration for each solution was multiplied by 0.802 , which converts the concentrations from the mesylate salt form to the free-base form (LB20304). The relevant stock solutions were diluted with methanol to give final spiking solutions of $1,2.5,4,10,25,40$, and $50 \mu \mathrm{g} / \mathrm{ml}$. Aliquots (10 $\mu \mathrm{l})$ of the spiking solutions were dispensed into mouse control serum $(50 \mu \mathrm{l})$ and control lung tissue $(50 \mathrm{mg})$ to give calibration standards equivalent to $0.2,0.5,0.8,1.0$, $2.0,5.0,8.0$, and $10 \mu \mathrm{g} / \mathrm{ml}$ of mouse serum and $0.02,0.5,0.8,2.0,5.0,8.0$, and 10 $\mu \mathrm{g} / \mathrm{g}$ of lung.

Serum samples $(50 \mu \mathrm{l})$ or lung tissue samples $(20$ to $50 \mathrm{mg}$ of lung tissue powder weighed exactly) were placed in labeled, silanized glass tubes; and $10 \%$ zinc sulfate $(25 \mu \mathrm{l})$ was added, followed by the addition of $100 \mu \mathrm{l}$ of methanol. The contents of the tubes were then mixed for approximately $30 \mathrm{~s}$, and the tubes were centrifuged at $1,500 \times g$ for $20 \mathrm{~min}$ at $4^{\circ} \mathrm{C}$. The supernatant (about $95 \mu \mathrm{l}$ ) was transferred into clean, tapered autosampler vials, and $20 \mu \mathrm{l}$ of this was injected into a high-performance liquid chromatographic system. Determination of antibiotic concentrations was performed with an octadecyl silyl column (Novapak $\mathrm{C}_{18}$; 4.6 by $150 \mathrm{~mm}$; Waters, Milford, Mass.) coupled with spectrofluorometric detection at 280 and $415 \mathrm{~nm}$ for the excitation and the emission wavelengths, respectively. The mobile phase was a mixture of acetonitrile, sodium citrate buffer solution ( $\mathrm{pH} 3.5)$, and water $(22 / 15 / 63$; vol/vol) with $0.1 \%$ trifluoroacetic acid adjusted to $\mathrm{pH} 4$. The flow rate was $1.0 \mathrm{ml} / \mathrm{min}$. The limit of quantitation was raised to $0.2 \mu \mathrm{g} / \mathrm{ml}$, and the linearity was established over concentration ranges of 0.2 to $10.0 \mu \mathrm{g} / \mathrm{ml}$ and 0.5 to $10.0 \mu \mathrm{g} / \mathrm{g}$ for the serum and lung tissue samples, respectively. The coefficients of variation for the quality controls were less than $10 \%$ for the serum and lung tissue samples. The PK parameters for trovafloxacin were evaluated as described elsewhere (8).

PK analysis was based on a noncompartmental model (WinNonlin version 1.1; Pharsight, Mountain View, Calif.). The maximum concentrations in serum 
TABLE 2. Analysis of first-step mutants generated upon exposure to gemifloxacin in vitro ${ }^{a}$

\begin{tabular}{llllllll}
\hline \multirow{2}{*}{ Strain } & \multicolumn{4}{c}{ MIC $(\mu \mathrm{g} / \mathrm{ml})$} & & \multicolumn{2}{c}{ Sequence } \\
\cline { 2 - 4 } \cline { 7 - 8 } \cline { 7 - 8 } & GEM & MXF & EtBr & NOR & & gyrA & \multicolumn{1}{c}{ parC } \\
\hline 1427 & 0.06 & 0.5 & 8 & 8 & & WT (Ser81) & WT (Ser79) \\
Ge14-R1 & 0.125 & 0.5 & 8 & 32 & & ND & ND \\
Ge14-R2 & 0.125 & 0.5 & 8 & 32 & & WT & Ser79Phe \\
Ge14-R3 & 0.125 & 0.5 & 8 & 64 & & ND & Asp83Asn \\
Ge14-R4 & 0.125 & 0.5 & 8 & 32 & & ND & Asp83Asn \\
\hline
\end{tabular}

${ }^{a}$ Abbreviations: GEM, gemifloxacin; MXF, moxifloxacin; EtBr, ethidium bromide; NOR, norfloxacin; WT, wild type; ND, not determined.

$\left(C_{\max }\right)$ were measured experimentally, while the area under the time-versusserum concentration curve (AUC) from 0 to $24 \mathrm{~h}\left(\mathrm{AUC}_{0-24}\right)$ and terminal half-life $\left(t_{1 / 2}\right)$ were calculated by using WinNonlin software.

Statistical analysis. Survival curve data were analyzed by using the nonparametric Mantel-Cox log-rank test. $P$ values of $\leq 0.05$ were considered statistically significant.

\section{RESULTS}

Activity of gemifloxacin against $S$. pneumoniae strains with defined target mutations. The MICs for the selected strains are shown in Table 1. Gemifloxacin displayed excellent in vitro activity against the virulent penicillin-susceptible wild-type strain of $S$. pneumoniae (P-4241). Its activity was 4 times greater than those of trovafloxacin and moxifloxacin, 16 times greater than that of sparfloxacin, 32 times greater than that of ciprofloxacin, and 256 times greater than that of norfloxacin. The gemifloxacin and trovafloxacin MICs for the parC mutant, strain C42-R2 (Ser79Tyr), increased two- and fourfold, respectively. For gyr $A$ mutant Sp42-R1 (Ser81Tyr), the gemifloxacin, moxifloxacin, and sparfloxacin MICs increased twofold, while the ciprofloxacin, norfloxacin, and trovafloxacin MICs remained unaffected. Mutant C42-Sp6, which had mutations in $\operatorname{parC}$ and gyrA, showed stronger increases in resistance, with the MICs of all quinolones tested being 16- to 64-fold higher than those observed for wild-type strain P-4241. Gemifloxacin has a lower MIC $(0.5 \mu \mathrm{g} / \mathrm{ml})$ than the other drugs for the mutant with the gyrA and parC double mutations. With the exception of the sparfloxacin MICs, the MICs of all quinolones increased twoto fourfold for efflux mutant N42-6R1. The gemifloxacin MICs for the clinical strain carrying a parE mutation (strain 2500) increased 2-fold, while the trovafloxacin and ciprofloxacin MICs increased 4- and 16-fold, respectively. The gemifloxacin MIC $(1 \mu \mathrm{g} / \mathrm{ml})$ for the clinical strain carrying a triple mutation (strain 2759) increased 32-fold, while the ciprofloxacin and trovafloxacin MICs increased 64- and 128-fold, respectively.

In vitro selection of $S$. pneumoniae strains resistant to gemifloxacin. Mutants were selected from strain 1427 on plates containing $0.125 \mu \mathrm{g}$ of gemifloxacin per ml. After $48 \mathrm{~h}$ of incubation, resistant colonies were selected at a frequency of $3 \times$ $10^{-9}$. Four colonies from strain 1427 (Ge14-R1 to Ge14-R4) were tested for their resistance profiles and the acquisition of mutations in the QRDRs of parC and gyrA (Table 2). The MICs of gemifloxacin and norfloxacin were increased for all four colonies derived from strain 1427. Susceptibilities to ethidium bromide, a substrate of the PmrA efflux pump (19), remained unaffected. The parC QRDRs of three mutants were sequenced. Strain Ge14-R2 had a Ser-to-Phe substitution at position 79, while mutants Ge14-R3 and Ge14-R4 had acquired an Asp-to-Asn substitution at position 83. Although gemifloxacin MICs were equally affected by mutations in gyr $A$ and parC (Table 1), parC mutations were preferentially selected upon exposure to gemifloxacin (Table 2).

In vivo studies. (i) PK data. To establish the most appropriate antibiotic treatment, we first determined the gemifloxacin concentrations in serum and lung tissue. The total drug concentrations in serum and lung tissue measured after administration of a single s.c. injection of $25 \mathrm{mg}$ of gemifloxacin per $\mathrm{kg}$ in uninfected animals (Fig. 1A) were similar to those in mice infected with virulent strain P-4241 (Fig. 1B). The AUCs and $t_{1 / 2} \mathrm{~S}$ were also not significantly affected by the infection status (Table 3), while for trovafloxacin the values of these PK parameters were two to three times higher than those in control animals. The $C_{\max }$ and AUCs of trovafloxacin were higher than those of gemifloxacin in both infected and uninfected animals, and the total $\mathrm{AUC}$ at $24 \mathrm{~h}\left(\mathrm{AUC}_{24}\right) / \mathrm{MIC}$ ratios were also higher with trovafloxacin in infected animals, but gemi-
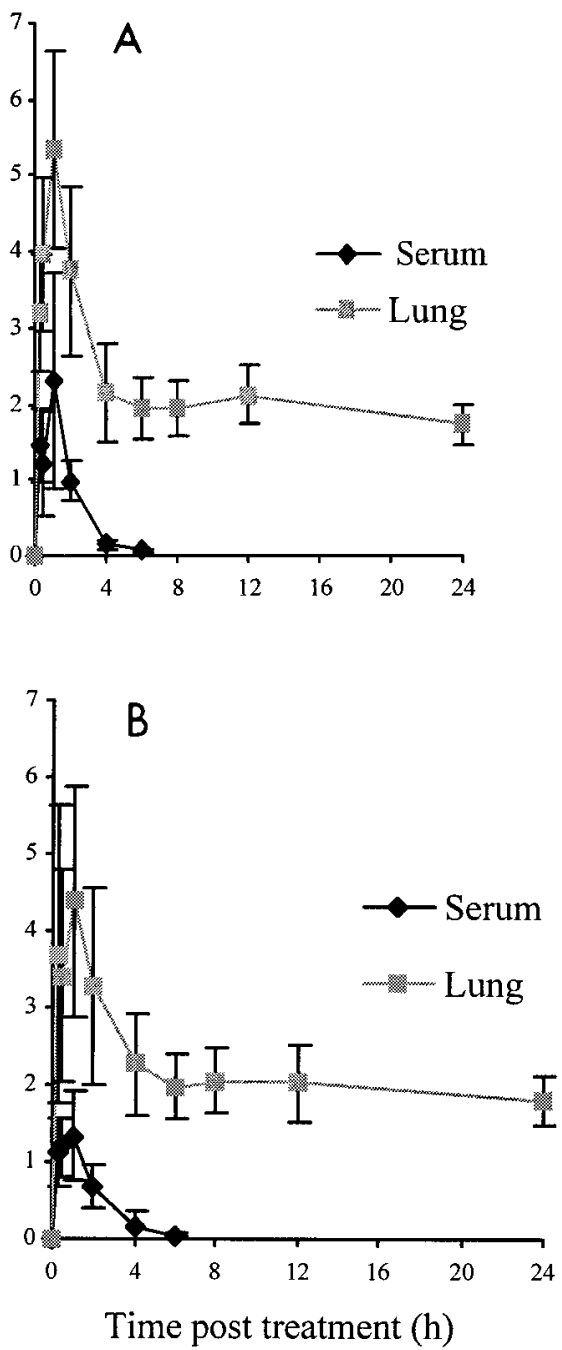

FIG. 1. Gemifloxacin concentrations in serum and lungs of uninfected $(\mathrm{A})$ and infected $(\mathrm{B})$ mice. 
TABLE 3. PK and PK-pharmacodynamic parameters for serum and lung tissues of immunocompetent control and infected mice after administration of a single s.c. dose of gemifloxacin or trovafloxacin at $25 \mathrm{mg} / \mathrm{kg}$

\begin{tabular}{|c|c|c|c|c|c|c|}
\hline $\begin{array}{l}\text { Mouse group, drug, and } \\
\text { compartment }\end{array}$ & $\begin{array}{c}C_{\max } \\
(\mu \mathrm{g} / \mathrm{ml} \text { or } \mu \mathrm{g} / \mathrm{g})\end{array}$ & $\underset{\text { ratio }}{C_{\max } / \mathrm{MIC}}$ & $\begin{array}{c}\mathrm{C}_{24} \mathrm{~h}^{a} \\
(\mu \mathrm{g} / \mathrm{ml} \text { or } \mu \mathrm{g} / \mathrm{g})\end{array}$ & $\begin{array}{l}\mathrm{AUC}_{0-24} \\
(\mu \mathrm{g} \cdot \mathrm{h} / \mathrm{ml})\end{array}$ & $\begin{array}{l}\text { AUC/MIC } \\
\text { ratio }\end{array}$ & $t_{1 / 2}(\mathrm{~h})$ \\
\hline \multicolumn{7}{|l|}{ Uninfected control } \\
\hline \multicolumn{7}{|l|}{ Gemifloxacin } \\
\hline Serum & $2.4 \pm 1.4^{b}$ & & & $4.4 \pm 1.4$ & & $1.0 \pm 0.2$ \\
\hline Lung & $5.3 \pm 1.3$ & & $1.72 \pm 0.03$ & $49.1 \pm 9.7$ & & $20.7 \pm 6.9$ \\
\hline \multicolumn{7}{|l|}{ Trovafloxacin } \\
\hline Serum & $4.2^{c}$ & & 0.01 & 19 & & 2.8 \\
\hline Lung & 24.2 & & 0.43 & 155 & & 4.3 \\
\hline \multicolumn{7}{|c|}{ Mice infected with strain P- $4241^{d}$} \\
\hline \multicolumn{7}{|l|}{ Gemifloxacin } \\
\hline Serum & $1.7 \pm 1.4$ & 56.7 & & $3.4 \pm 0.8$ & 113 & $1.1 \pm 0.2$ \\
\hline Lung & $4.7 \pm 1.9$ & 157 & $1.81 \pm 0.31$ & $43.8 \pm 15.1$ & 1,460 & $28.2 \pm 19.0$ \\
\hline \multicolumn{7}{|l|}{ Trovafloxacin } \\
\hline Serum & 5.7 & 45.6 & 0.5 & 49 & 392 & 7.4 \\
\hline Lung & 21.2 & 170 & 3.7 & 250 & 2,000 & 11.6 \\
\hline
\end{tabular}

${ }^{a} \mathrm{C}_{24}$, total drug concentration at $24 \mathrm{~h}$ posttreatment.

${ }^{b}$ Values for gemifloxacin are means and standard deviations calculated for six serum and lung tissue samples taken $0.25,0.5,1,2,4,6,8,12$, and 24 h postdosing with gemifloxacin.

${ }^{c}$ Values for trovafloxacin are for six pooled samples of serum and lung tissue taken at the same times postdosing used for gemifloxacin (see footnote $b$ above).

${ }^{d}$ The gemifloxacin MIC for strain P-4141 was $0.03 \mu \mathrm{g} / \mathrm{ml}$; the trovafloxacin MIC was $0.125 \mu \mathrm{g} / \mathrm{ml}$.

floxacin had longer $t_{1 / 2} \mathrm{~s}$ than trovafloxacin in the lungs of both the control and the infected animals (Table 3).

(ii) Survival. All untreated control mice died within 3 to 6 days after challenge with the different strains. Gemifloxacin was used to treat mice infected with virulent $S$. pneumoniae strain P-4241 and its fluoroquinolone-resistant derivatives (Table 4). Six injections of gemifloxacin at 50 and $25 \mathrm{mg} / \mathrm{kg}$ yielded rates of survival of 100 and $93 \%$, respectively, among mice infected with wild-type strain P-4241, while $80 \%$ were protected with the $12.5-\mathrm{mg} / \mathrm{kg}$ dose. Even with the lowest dose of $6.25 \mathrm{mg} / \mathrm{kg}$, a $40 \%$ survival rate was observed (Fig. 2A). Gemifloxacin at 50 and $25 \mathrm{mg} / \mathrm{kg}$ was also effective in mice infected with parC mutant C42-R2 (survival rates, 100 and 69\%, respec- tively) (Fig. 2B) and mice infected with gyrA mutant Sp42-R1 (survival rate, 100\%) (Fig. 2C). Lower survival rates for the parC mutant than for the wild type were found at both 12.5 and $6.25 \mathrm{mg} / \mathrm{kg}$ (survival rates, 36 and $7 \%$, respectively), while the survival rates for mice infected with the gyr $A$ mutant and treated with the same doses remained relatively high (79 and $64 \%$, respectively). All animals infected with efflux mutant N42-6R1 and parE mutant 2500 (Table 4) survived when they were treated with gemifloxacin at 25 and $50 \mathrm{mg} / \mathrm{kg}$. Gemifloxacin remained effective at 50 and $75 \mathrm{mg} / \mathrm{kg}$, with survival rates of 40 and $50 \%$, respectively, when animals were infected with the mutant with the double mutation, C42-Sp6 (Fig. 2D), and was slightly effective at $50 \mathrm{mg} / \mathrm{kg}$, with $25 \%$ survival among the

TABLE 4. Survival rates at 10 days postinfection in animals treated with gemifloxacin, trovafloxacin, or ciprofloxacin ${ }^{a}$

\begin{tabular}{|c|c|c|c|c|c|c|c|c|c|}
\hline \multirow{3}{*}{ Strain } & \multicolumn{9}{|c|}{$\%$ Survival } \\
\hline & \multicolumn{3}{|c|}{ Gemifloxacin } & \multicolumn{4}{|c|}{ Trovafloxacin } & \multicolumn{2}{|c|}{ Ciprofloxacin } \\
\hline & $12.5 \mathrm{mg} / \mathrm{kg}$ & $25 \mathrm{mg} / \mathrm{kg}$ & $\overline{50 \mathrm{mg} / \mathrm{kg}}$ & $12.5 \mathrm{mg} / \mathrm{kg}$ & $25 \mathrm{mg} / \mathrm{kg}$ & $50 \mathrm{mg} / \mathrm{kg}$ & $200 \mathrm{mg} / \mathrm{kg}$ & $100 \mathrm{mg} / \mathrm{kg}$ & $250 \mathrm{mg} / \mathrm{kg}$ \\
\hline $\mathrm{P}-4241$ & 80 & $93^{b}$ & $100^{c}$ & 91 & 100 & & & 50 & 77 \\
\hline parC & $36^{d}$ & $69^{e}$ & $100^{f}$ & 14 & 100 & 100 & & 0 & 27 \\
\hline gyrA & $79^{g}$ & $100^{g}$ & $100^{g}$ & 46 & 92 & 100 & & 0 & 80 \\
\hline parC gyrA & 0 & 0 & $40^{h}$ & & & 0 & 0 & & 0 \\
\hline parE & 92 & $100^{i}$ & 100 & 55 & 56 & 90 & & & \\
\hline Efflux mutant & $92^{j}$ & $100^{k}$ & $100^{k}$ & 83 & 100 & 100 & & 30 & 78 \\
\hline
\end{tabular}

${ }^{a}$ Treatments were initiated with gemifloxacin and trovafloxacin at $18 \mathrm{~h}$ postchallenge and with ciprofloxacin at $6 \mathrm{~h}$ postchallenge. Survival curves were compared by using the nonparametric Mantel-Cox log-rank test.

${ }^{b}$ Significant difference $(P<0.05)$ between gemifloxacin and ciprofloxacin at $100 \mathrm{mg} / \mathrm{kg}$.

${ }^{c}$ Significant difference $(P<0.01)$ between gemifloxacin and ciprofloxacin at $100 \mathrm{mg} / \mathrm{kg}$.

${ }^{d}$ Significant difference $(P<0.001)$ between gemifloxacin and ciprofloxacin at $100 \mathrm{mg} / \mathrm{kg}$.

${ }^{e}$ Significant difference $(P<0.01)$ between gemifloxacin and ciprofloxacin at $250 \mathrm{mg} / \mathrm{kg}$.

${ }^{f}$ Significant difference $(P<0.0001)$ between gemifloxacin and ciprofloxacin at $250 \mathrm{mg} / \mathrm{kg}$.

${ }^{g}$ Significant difference $(P<0.0001)$ between gemifloxacin and ciprofloxacin at $100 \mathrm{mg} / \mathrm{kg}$.

${ }^{h}$ Significant difference $(P<0.0001)$ between gemifloxacin and trovafloxacin at $200 \mathrm{mg} / \mathrm{kg}$.

${ }^{i}$ Significant difference $(P<0.05)$ between gemifloxacin and trovafloxacin at $25 \mathrm{mg} / \mathrm{kg}$.

${ }^{j}$ Significant difference $(P<0.01)$ between gemifloxacin and ciprofloxacin at $100 \mathrm{mg} / \mathrm{kg}$.

${ }^{k}$ Significant difference $(P<0.001)$ between gemifloxacin and ciprofloxacin at $100 \mathrm{mg} / \mathrm{kg}$. 
A: $\mathbf{P}-4241$

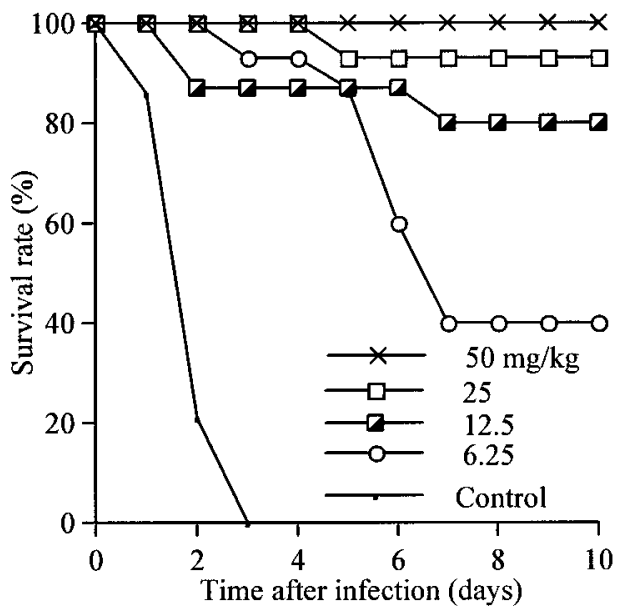

C: GyrA

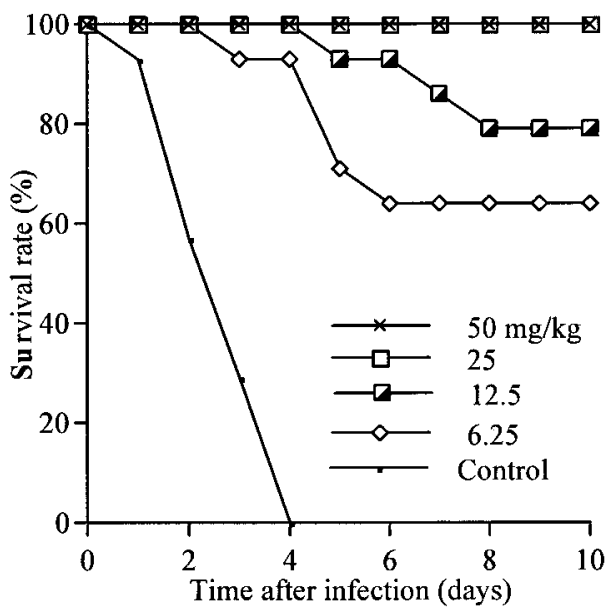

B: ParC

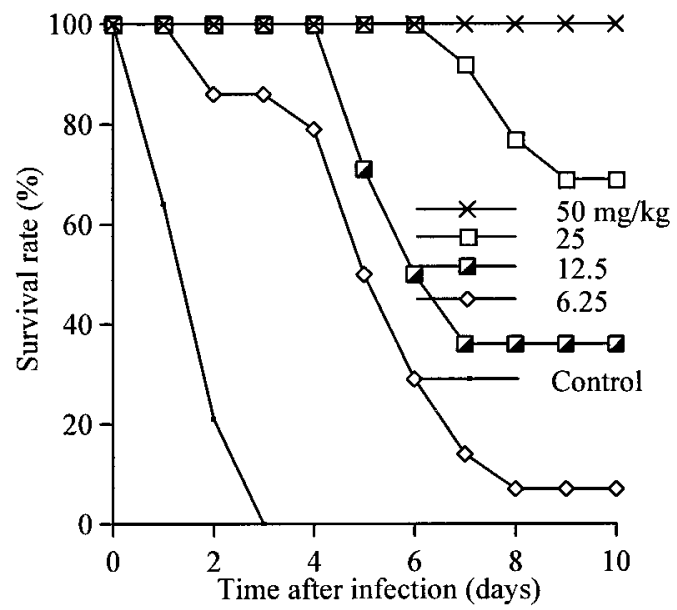

D: GyrAParC

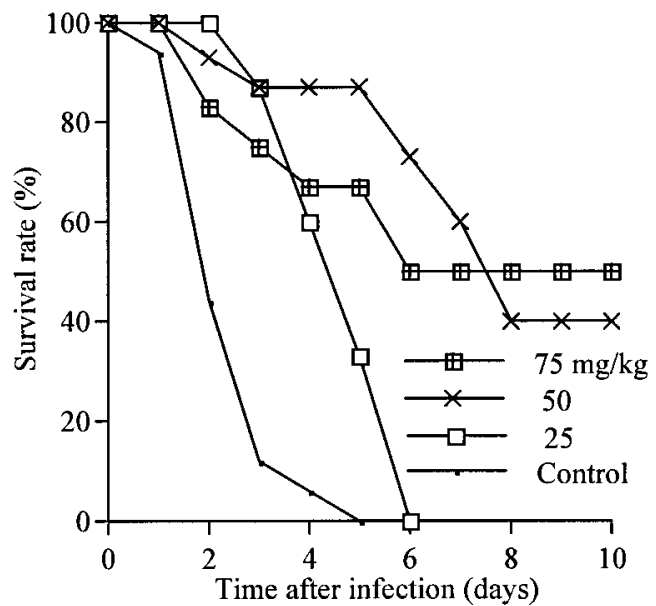

FIG. 2. Survival rates of gemifloxacin-treated mice challenged with either a virulent penicillin-susceptible pneumococcal strain or isogenic mutant derivatives. (A) P-4241 (wild type); (B) C42-R2 (parC); (C) Sp42-R1 (gyrA); (D) C42-Sp6 (gyrA parC).

mice infected with the mutant with a triple mutation (P-2759) (data not shown)

Trovafloxacin at doses of 50 and $25 \mathrm{mg} / \mathrm{kg}$ was as effective as gemifloxacin in mice infected with the wild type and mutants with single mutations (gyrA, parC, and efflux mutants), while gemifloxacin was significantly more effective than trovafloxacin at $25 \mathrm{mg} / \mathrm{kg}$ against the parE mutant $(P<0.05)$. Moreover, treatment regimens with very high doses of trovafloxacin $(100$ and $200 \mathrm{mg} / \mathrm{kg}$ ) were totally ineffective ( $0 \%$ survival) against mutant C42Sp6 with double mutations in parC and gyrA. Gemifloxacin at $50 \mathrm{mg} / \mathrm{kg}$ was significantly more effective than trovafloxacin at $200 \mathrm{mg} / \mathrm{kg}(P<0.0001)$ against the mutant with double mutations (Table 4).

Comparison with ciprofloxacin showed that only $50 \%$ of mice infected with the wild type strain P-4241 were protected by this quinolone, despite treatment with a high dose of 100 $\mathrm{mg} / \mathrm{kg}$ and early treatment at $6 \mathrm{~h}$ after challenge. A high dose of $250 \mathrm{mg} / \mathrm{kg}$ yielded about $80 \%$ survival in animals infected with the wild-type strain, the gyrA mutant, and the efflux mutant and only $27 \%$ survival in animals infected with the parC mutant, while none of the mice survived when they were challenged with $\mathrm{C} 42 \mathrm{Sp} 6$, which carried the double mutation gyrA and $\operatorname{parC}$. None of the animals survived when the first treatment was delayed until $18 \mathrm{~h}$ postinfection. Gemifloxacin was significantly more effective than ciprofloxacin against all study strains (Table 4).

(iii) Bacterial clearance. Bacterial growth in the lungs of mice infected with strain P-4241 was observed from $22 \mathrm{~h}$ postinfection $\left(5.2 \log _{10} \mathrm{CFU} / \mathrm{ml}\right)$ until death at $67 \mathrm{~h}$ postinfection $\left(8 \log _{10} \mathrm{CFU} / \mathrm{ml}\right)$. Blood cultures were always positive for the untreated controls. The lungs and blood of mice infected with wild-type strain P-4241 were completely cleared after two injections of gemifloxacin at 50 or $25 \mathrm{mg} / \mathrm{kg}$ and four injections at $12.5 \mathrm{mg} / \mathrm{kg}$. At the lowest dose, $6.25 \mathrm{mg} / \mathrm{kg}$, bacterial regrowth in both the lungs and blood was observed $13 \mathrm{~h}$ after six treatments (Table 5). In animals infected with the gyrA or parC 
TABLE 6. Analysis of wild-type- and mutant-derived strains isolated from untreated controls and gemifloxacin-treated mice ${ }^{a}$

\begin{tabular}{|c|c|c|c|c|c|c|c|}
\hline \multirow{2}{*}{ Strain } & \multicolumn{5}{|c|}{ MIC $(\mu \mathrm{g} / \mathrm{ml})$} & \multicolumn{2}{|c|}{ Sequence } \\
\hline & NOR & CIP & GEM & SFX & $\mathrm{EtBr}$ & gyr $A$ & $\operatorname{parC}$ \\
\hline 4241 & 8 & 1 & 0.03 & 0.5 & 4 & Ser81 & Ser79, Arg95 \\
\hline $\mathrm{C} 1, \mathrm{C} 2$ & 8 & $1 / 2$ & 0.03 & 0.5 & 4 & ND & ND \\
\hline T1-1, T1-2 & 64 & 8 & 0.06 & 1 & $4 / 8$ & ND & $\begin{array}{l}\text { Ser79Tyr + } \\
\text { Arg95Cys }\end{array}$ \\
\hline $\begin{array}{l}\mathrm{C} 42-\mathrm{R} 2 \\
\quad(\operatorname{par} C)\end{array}$ & 64 & 4 & 0.06 & 2 & 8 & Ser81 & Ser79Tyr \\
\hline $\mathrm{C} 1, \mathrm{C} 2$ & 64 & 8 & 0.06 & 2 & 8 & ND & ND \\
\hline $\mathrm{T} 1, \mathrm{~T} 2$ & 64 & 8 & 0.06 & 2 & 8 & ND & ND \\
\hline $\begin{array}{r}\mathrm{Sp} 42-\mathrm{R} 1 \\
(\text { gyrA })\end{array}$ & 16 & ND & 0.06 & 2 & ND & Ser81Tyr & ND \\
\hline $\mathrm{C} 1, \mathrm{C} 2$ & 16 & ND & 0.06 & 2 & ND & Ser81Tyr & ND \\
\hline $\mathrm{T} 1$ to $\mathrm{T} 3$ & 128 & ND & 0.5 & 8 & ND & Ser81Tyr & $\begin{array}{r}\text { Ser79Tyr + } \\
\text { Arg95Cys }\end{array}$ \\
\hline $\mathrm{T} 4$ to $\mathrm{T} 6$ & 32 & ND & 0.25 & 4 & ND & Ser81Tyr & Arg95Cys \\
\hline $\begin{array}{l}\text { C42-Sp6 } \\
\quad(\text { gyrA parC) }\end{array}$ & 128 & 64 & 0.5 & 32 & ND & Ser81Tyr & Ser79Tyr \\
\hline $\mathrm{C} 1, \mathrm{C} 2$ & 128 & 64 & 0.5 & 32 & ND & ND & ND \\
\hline $\mathrm{T} 1$ to $\mathrm{T} 4$ & 128 & 64 & 0.5 & $32 / 64$ & ND & ND & ND \\
\hline N42-6R1 & $16-32$ & 4 & 0.06 & 1 & 16 & ND & ND \\
\hline $\mathrm{C} 1, \mathrm{C} 2$ & 16 & 4 & 0.06 & 1 & 16 & ND & ND \\
\hline $\mathrm{T} 1, \mathrm{~T} 2$ & $16 / 64$ & $4 / 8$ & 0.06 & 1 & 16 & ND & $\begin{array}{r}\text { Ser79Tyr + } \\
\text { Arg95Cys }\end{array}$ \\
\hline
\end{tabular}

${ }^{a}$ The mice were treated with gemifloxacin at $6.25 \mathrm{mg} / \mathrm{kg}$. Abbreviations: C, control mice; T, treated mice; NOR, norfloxacin; CIP, ciprofloxacin; GEM gemifloxacin; SFX, sparfloxacin; EtBr, ethidium bromide; ND, not determined.

mutant, the lungs and blood were completely cleared after two injections of gemifloxacin at 50 and $25 \mathrm{mg} / \mathrm{kg}$ but not after two injections at $12.5 \mathrm{mg} / \mathrm{kg}$. Bacterial clearance from the lungs and blood was also incomplete when animals infected with the gyr $A$ $\operatorname{parC}$ (Table 5) or gyrA parC parE mutants were treated with 50 $\mathrm{mg}$ of gemifloxacin per $\mathrm{kg}$. Bacterial clearance correlated with survival.

(iv) In vivo emergence of resistance. Emergence of resistance was evaluated in infected animals, which were either untreated or treated with gemifloxacin (Table 6).

In mice infected with the wild-type strain and treated with gemifloxacin at $6.25 \mathrm{mg} / \mathrm{kg}$, resistance emerged in two clones of one isolate (clones T1-1 and T1-2), with each clone carrying two $\operatorname{parC}$ mutations: the frequent Ser79Tyr substitution and the rare Arg95Cys substitution. The MICs for these clones were higher than those for isolates from mice infected with the wild type or the untreated controls. This is in agreement with the results of the in vitro study, in which parC mutants were selected after exposure to gemifloxacin.

No significant changes in MICs were observed for strains isolated from mice infected with parC mutant C42-R2 when the mice were either treated or not treated with gemifloxacin. The resistance phenotype was thus conserved in all clones analyzed, suggesting that the parC mutation is stably maintained in vivo, even in the absence of antibiotic pressure in the case of the untreated control mice.

In mice infected with gyrA mutant Sp42-R1, the MIC profiles for all strains isolated from untreated control mice remained unchanged. However, six of six colonies isolated from gemi- 
floxacin-treated animals displayed newly acquired mutations in parC. Three clones (clones T4 to T6) had a single parC mutation (Arg95Cys), while three other clones (clones T1 to T3) had two mutations in parC (Ser79Tyr and Arg95Cys). These results show that a gyr $A$ mutation facilitates the selection of subsequent mutations in parC. With the exception of clone T4, the MICs for the clones containing the two parC mutations were higher than those for the clones carrying only one mutation.

No significant changes in MICs were observed for isolates from untreated and gemifloxacin-treated animals infected with the mutant with the double mutation, C42-Sp6. The QRDRs of these strains were therefore not sequenced.

The norfloxacin and ciprofloxacin MICs were increased for one of three colonies isolated from gemifloxacin-treated animals infected with efflux mutant N42-6R1. This clone (clone T2) had acquired a new parC mutation.

\section{DISCUSSION}

In our study, gemifloxacin displayed the lowest MIC for a virulent penicillin-susceptible wild-type strain of $S$. pneumoniae (P-4241), followed by the MICs of trovafloxacin, moxifloxacin, sparfloxacin, ciprofloxacin, and norfloxacin. Additionally, gemifloxacin had the lowest MICs for quinolone-resistant pneumococci, irrespective of the quinolone resistance mechanism. This was the case for quinolone-resistant mutants harboring a single mutation in gyrA (Ser81Tyr), parC (Ser79Tyr), and parE (Ile460Val or Asp435Asn) as well as for an efflux mutant. Gemifloxacin also demonstrated the lowest MICs for strains harboring double mutations ( $\operatorname{par} C$ and gyrA) or triple mutations (parC, gyrA, and paE). Our data are in accordance with those of several other investigators $(10,12,14,22,25,29,36$, 38 ), which indicate that the rank order of the in vitro potencies of quinolones against $S$. pneumoniae is as follows: gemifloxacin $\geq$ garenoxacin, clinafloxacin $>$ moxifloxacin $>$ gatifloxacin, trovafloxacin, and grepafloxacin $>$ sparfloxacin $>$ levofloxacin $>$ ciprofloxacin. Gemifloxacin was more effective than these quinolones against laboratory strains carrying mutations in parC (Ser79Tyr, Ser79Phe, Asp83Asn, or Ala189Val); gyrA (Glu87Lys, Ser81Phe, or Ser83Tyr); gyrB (Glu474Lys); parE (Asp435Val or Ile460Val); the efflux mechanism; parC and gyr $A$; and $\operatorname{par} C$, gyr $A$, and parE. In addition, gemifloxacin demonstrated a higher level of activity than moxifloxacin, gatifloxacin, ciprofloxacin, and levofloxacin against penicillin-susceptible and -resistant $S$. pneumoniae strains (38).

Previous reports (31) showed that exposure to subinhibitory concentrations of gemifloxacin in vitro selected mutants with single modifications in parC (S79Phe, Asp83Asn, or Lys137Asn), gyrA (Ser81Phe, Ser81Tyr, Glu85Ala, or Glu85Lys), or parE (Arg447Ser or Ile460Val). Boos et al. (9) also described multistep resistance selection in $S$. pneumoniae with subinhibitory concentrations of gemifloxacin and five other quinolones. Derived clones had single mutations in $\operatorname{gyr} A$ or $\operatorname{par} C$ alone or double mutations in $g y r A$ and $\operatorname{par} C$ with the classical alterations in ParC (Ser79Phe or Tyr and Asp83Tyr) and GyrA (Ser81Phe or Tyr). Heaton et al. (23) also showed that gemifloxacin targets both enzymes. Morrissey and George (29) reported that gemifloxacin has a higher affinity for topoisomerase IV (ParC, ParE) than for gyrase (GyrA, GyrB).
In our in vitro experiments, we found that gemifloxacin preferentially selects for mutations in the parC gene (Ser79Phe or Asp83Asn). This is in agreement with our in vivo results, in which parC mutants selected after treatment with gemifloxacin carried the frequent Ser79Tyr substitution and the rare Arg95Cys substitution. Surprisingly, with the wild-type strain, the gyrA mutant, and the efflux mutant, gemifloxacin treatment yielded strains that carried two mutations in the parC gene. This could mean that at least two cycles of selection occurred in the animal during repeated gemifloxacin administration. Indeed, the mutant prevention concentration of gemifloxacin has been determined in vitro by Hansen et al. (21) and was shown to be equal to $1 \mu \mathrm{g} / \mathrm{ml}$, which is close to the maximal concentrations in serum of 1.7 and $2.4 \mu \mathrm{g} / \mathrm{ml}$ determined in our study, which might explain the possible selection of mutants in vivo with the lowest gemifloxacin dose of $6.25 \mathrm{mg} / \mathrm{kg}$. Of note, in vitro studies suggested that mutations in $\operatorname{gyr} A$ or $\operatorname{par} C$, or even both genes, generated only a minor biological cost for $S$. pneumoniae, since the growth rates of the mutants were comparable to those of the wild type (20), an observation confirming the maintenance of these mutations in strains isolated from untreated control animals.

Our in vivo results showed that gemifloxacin is as effective as trovafloxacin against the wild-type strain. This efficacy was not adversely affected by quinolone resistance due to a single mutation (parC, gyrA, parE, or an efflux mutation). However, the main differences in efficacy were observed against strains carrying multiple target mutations. Even at the very high dose of $200 \mathrm{mg} / \mathrm{kg}$, trovafloxacin was completely ineffective against the mutant with the double mutation, whereas gemifloxacin provided $50 \%$ survival against this mutant at only $75 \mathrm{mg} / \mathrm{kg}$.

The in vivo efficacy of gemifloxacin was mainly due to its high in vitro potency against wild-type and fluoroquinoloneresistant $S$. pneumoniae strains. However, other factors, and particularly PK-pharmacodynamic parameters, may explain its in vivo efficacy. For fluoroquinolones, data suggest that a total $\mathrm{AUC}_{24} / \mathrm{MIC}$ ratio of 100 to 125 correlates with optimal clinical and microbiological outcomes in seriously ill patients infected with gram-negative enteric pathogens or Pseudomonas aeruginosa (18). Ambrose et al. (2) observed a relationship between a free drug $\mathrm{AUC}_{24} / \mathrm{MIC}$ ratio $>33.7$ and the microbiological response in patients with community-acquired respiratory tract infections involving $S$. pneumoniae and treated with levofloxacin or gatifloxacin. From these results, the total drug $\mathrm{AUC}_{24} /$ MIC ratios for the two drugs could be extrapolated to 42 and 44 , respectively, since in humans the levels of serum protein binding are equal to 24 and $20 \%$ for levofloxacin and gatifloxacin, respectively.

Our data suggest that with the $25-\mathrm{mg} / \mathrm{kg}$ dose, the total $\mathrm{AUC}_{24} / \mathrm{MIC}$ ratio of 113 against $\mathrm{P}-4241$ was associated with a survival rate of $93 \%$ and an $\mathrm{AUC}_{24} / \mathrm{MIC}$ ratio of 56.5 against $\operatorname{par} C$ and $g y r A$ mutants was associated with survival rates of 69 and $100 \%$, respectively. Conversely, with the $6.25-\mathrm{mg} / \mathrm{kg}$ dose, the total $\mathrm{AUC}_{24} / \mathrm{MIC}$ ratio was equal to 28.5 and was associated with poor efficacy and the emergence of resistant mutants.

However, even though the gemifloxacin MICs were similar for the parC and gyrA mutants, gemifloxacin at $25 \mathrm{mg} / \mathrm{kg}$ showed decreased efficacy against the $\operatorname{par} C$ mutant but not against the gyrA mutant. This suggests that ParC is the more important target for gemifloxacin, which could explain the 
preferential selection of parC mutants during gemifloxacin therapy.

Allen et al. (1) studied the PKs and tolerability of gemifloxacin after administration of single oral doses to healthy volunteers. They found that the mean $C_{\max } \mathrm{s}$ increased with increasing dose: the mean \pm standard deviation $C_{\max }$ s were $1.48 \pm$ 0.39 and $3.86 \pm 1.09 \mu \mathrm{g} / \mathrm{ml}$ following the administration of 320 and 600-mg doses, respectively, which are expected to be effective. These concentrations are similar to that obtained with a dose of $25 \mathrm{mg} / \mathrm{kg}$ in mouse serum, with $C_{\max }$ equal to $2.4 \pm$ $1.4 \mu \mathrm{g} / \mathrm{ml}$ in noninfected animals. The serum AUC in our mouse model was equal to $4.4 \pm 1.4 \mu \mathrm{g} \cdot \mathrm{h} / \mathrm{ml}$ for the control animals, which is near that obtained in healthy volunteers after treatment with $160 \mathrm{mg}(5.48 \pm 1.24 \mu \mathrm{g} \cdot \mathrm{h} / \mathrm{ml})$.

In conclusion, gemifloxacin was effective in an experimental model of pneumococcal pneumonia induced by both quinolone-susceptible and quinolone-resistant strains of S. pneumoniae. However, the total $\mathrm{AUC}_{24} / \mathrm{MIC}$ ratio must be $>28.5$, as this ratio was found to be associated with poor efficacy and the emergence of resistant mutants. Moreover, at lower doses, gemifloxacin preferentially selects for parC mutants.

\section{ACKNOWLEDGMENTS}

This study was supported by a grant from SmithKline Beecham.

We thank M. Muffat-Joly and P. Jelazko for help with the statistical analysis and advice.

\section{REFERENCES}

1. Allen, A., E. Bygate, S. Oliver, M. Johnson, C. Ward, A. J. Cheon, Y. S. Choo, and I. C. Kim. 2000. Pharmacokinetics and tolerability of gemifloxacin (SB265805 ) after administration of single oral doses to healthy volunteers. Antimicrob. Agents Chemother. 44:1604-1608.

2. Ambrose, P. G., D. M. Grasela, T. H. Grasela, J. Passarell, H. B. Mayer, and P. F. Pierce. 2001. Pharmacodynamics of fluoroquinolones against Streptococcus pneumoniae in patients with community-acquired respiratory tract infections. Antimicrob. Agents Chemother. 45:2793-2797.

3. Appelbaum, P. C. 1992. Antimicrobial resistance in Streptococcus pneumoniae: an overview. Clin. Infect. Dis. 15:77-83.

4. Appelbaum, P. C. 1996. Emergence of resistance to antimicrobial agents in gram-positive bacteria. Pneumococci. Drugs 51(Suppl. 1):1-5.

5. Azoulay-Dupuis, E., E. Vallée, B. Veber, J. P. Bédos, J. Bauchet, and J. J. Pocidalo. 1992. In vivo efficacy of a new fluoroquinolone, sparfloxacin, against penicillin-susceptible and -resistant and multiresistant strains of Streptococcus pneumoniae in a mouse model of pneumonia. Antimicrob. Agents Chemother. 36:2698-2703.

6. Azoulay-Dupuis, E., J. P. Bédos, J. Mohler, G. Peytavin, R. Isturiz, P. Moine, V. Rieux, C. Cherbuliez, J. C. Péchère, B. Fantin, and T. Köhler. 2004 Activities of garenoxacin against quinolone-resistant Streptococcus pneumoniae strains in vitro and in a mouse pneumonia model. Antimicrob. Agents Chemother. 48:765-773.

7. Bartlett, J. G., R. F. Breiman, L. A. Mandell, T. M. File, D. Musher, and M. Fine. 2000. Community acquired pneumonia in adults: guidelines for management. Clin. Infect. Dis. 31:347-382

8. Bédos, J. P., V. Rieux, J. Bauchet, M. Muffat-Joly, C. Carbon, and E. Azoulay-Dupuis. 1998. Efficacy of trovafloxacin against penicillin-susceptible and multiresistant strains of Streptococcus pneumoniae in a mouse pneumonia model. Antimicrob. Agents Chemother. 42:862-867.

9. Boos, M., S. Mayer, A. Fisher, K. Kôhrer, S. Scheuring, S. Heisig, J. Verhoef, A. D. C. Fluit, and F. J. Schmitz. 2001. In vitro development of resistance to six quinolones in Streptococcus pneumoniae, Streptococcus pyogenes, and Staphylococcus aureus. Antimicrob. Agents Chemother. 45:938-942.

10. Boswell, F. J., J. M. Andrews, G. Jevons, and R. Wise. 2002. Comparison of the in vitro activities of several new fluoroquinolones against respiratory pathogens and their abilities to select fluoroquinolone resistance. J. Antimicrob. Chemother. 50:495-502.

11. Brenwald, N. P., M. J. Gill, and R. Wise. 1998. Prevalence of a putative efflux mechanism among fluoroquinolone-resistant clinical isolates of Streptococcus pneumoniae. Antimicrob. Agents Chemother. 42:2032-2035.

12. Broskey, J., K. Coleman, M. N. Gwynn, L. McLoskey, C. Traini, L. Voelker, and R. Warren. 2000. Efflux and target mutations as quinolone resistance mechanisms in clinical isolates of Streptococcus pneumoniae. J. Antimicrob. Chemother. 45:95-99.
13. Chen, D. K., A. McGeer, J. C. de Azavedo, D. E. Low, et al. 1999. Decreased susceptibility of Streptococcus pneumoniae in Canada. N. Engl. J. Med. 341: 233-239.

14. Davies, T. A., L. M. Kelly, G. A. Pankuck, K. M. Credito, M. R. Jacobs, and P. C. Appelbaum. 2000. Antipneumococcal activities of gemifloxacin compared to those of nine other agents. Antimicrob. Agents Chemother. 44: 304-310.

15. Dubois, J., and C. St-Pierre. 2000. Comparative in vitro activity and postantibiotic effect of gemifloxacin against Legionella spp. J. Antimicrob. Chemother. 45(Suppl. S1):41-46.

16. Duffy, L. B., D. Crabb, K. Searcey, and M. C. Kempf. 2000. Comparative potency of gemifloxacin, new quinolones, macrolides, tetracycline and clindamycin against Mycloplasma spp. J. Antimicrob. Chemother. 45(Suppl. S1): 29-33.

17. European Commission. 1986. Directive for the protection of vertebrate animals used for experimental and other scientific purposes (86/609/EEC) Off. J. C. Eur. Comm. L. 358:1-29.

18. Forrest, A., D. E. Nix, C. H. Ballow, T. F. Goss, M. C. Birmingham, and J. J. Schentag. 1993. Pharmacodynamics of intravenous ciprofloxacin in seriously ill patients. Antimicrob. Agents Chemother. 37:1073-1081.

19. Gill, M. J., N. P. Brenwald, and R. Wise. 1999. Identification of an efflux pump gene, pmrA, associated with fluoroquinolone resistance in Streptococcus pneumoniae. Antimicrob. Agents Chemother. 43:187-189.

20. Gillespie, S. H., L. L. Voelker, and A. Dickens. 2002. Evolutionary barriers to quinolone resistance in Streptococcus pneumoniae. Microb. Drug Resist. 8: $79-84$

21. Hansen, G. T., K. Metzler, K. Drlica, and J. M. Blondeau. 2003. Mutant prevention concentration of gemifloxacin for clinical isolates of Streptococcus pneumoniae. Antimicrob. Agents Chemother. 47:440-441.

22. Heaton, V. J., C. E. Goldsmith, J. E. Ambler, and L. M. Fisher. 1999. Activity of gemifloxacin against penicillin- and ciprofloxacin-resistant Streptococcus pneumoniae displaying topoisomerase- and efflux-mediated resistance mechanisms. Antimicrob. Agents Chemother. 43:2998-3000.

23. Heaton, V. J., J. E. Ambler, and L. M. Fisher. 2000. Potent antipneumococcal activity of gemifloxacin is associated with dual targeting of gyrase and topoisomerase IV, an in vivo target preference for gyrase, and enhanced stabilization of cleavable complex in vitro. Antimicrob. Agents Chemother. 44:3112-3117.

24. Janoir, C., V. Zeller, M. Kitzis, N. J. Moreau, and L. Gutman. 1996. Highlevel fluoroquinolone resistance in Streptococcus pneumoniae requires mutations in parC and gyrA. Antimicrob. Agents Chemother. 40:2760-2764.

25. Jorgensen, J. H., L. M. Weigel, J. M. Swenson, C. G. Whitney, M. J. Ferraro, and M. C. Tenover. 2000. Activities of clinafloxacin, gatifloxacin, gemifloxacin, and trovafloxacin against recent clinical isolates of levofloxacin-resistant Streptococcus pneumoniae. Antimicrob. Agents Chemother. 44: 2962-2968

26. King, A., J. May, G. French, and I. Phillips. 2000. Comparative in vitro activity of gemifloxacin. J. Antimicrob. Chemother. 45(Suppl. S1):1-12.

27. Lieberman, D., F. Schlaeffer, H. Boldur, D. Lieberman, S. Horowitz, M. Leinonen, O. Horowitz, E. Manor, and A. Porath. 1996. Multiple pathogens in adult patients admitted with community-acquired pneumonia: a one year prospective study of 346 consecutive patients. Thorax 51:179-184.

28. Moine, P., J. B. Vercken, S. Chevret, C. Chastang, P. Gajdos, and the French Study Group for Community-Acquired Pneumonia in the Intensive Care Unit. 1994. Severe community-acquired pneumonia. Etiology, epidemiology, and prognosis factors. Chest 105:1487-1495.

29. Morrissey, I., and J. T. George. 2000. Bactericidal activity of gemifloxacin and other quinolones against Streptococcus pneumoniae. J. Antimicrob. Chemother. 45(Suppl. S1):107-110.

30. Munoz, R., and A. G. De La Campa. 1996. ParC subunit of DNA topoisomerase IV of Streptococcus pneumoniae is a primary target of fluoroquinolones and cooperates with DNA gyrase A subunit in forming resistance phenotype. Antimicrob. Agents Chemother. 40:2252-2257.

31. Nagai, K., T. A. Davies, B. E. Dewasse, M. R. Jacobs, and P. C. Appelbaum. 2001. Single- and multi-step resistance selection study of gemifloxacin compared with trovafloxacin, ciprofloxacin, gatifloxacin and moxifloxacin in Streptococcus pneumoniae. J. Antimicrob. Chemother. 48:365-374.

32. National Committee for Clinical Laboratory Standards. 2000. Performance standards for antimicrobial disk susceptibility tests; approved standard, 7th ed., M2-A7, vol. 20, no. 1. National Committee for Clinical Laboratory Standards, Wayne, Pa.

33. Pallarés, R., J. Linarés, M. Vadillo, C. Cabellos, F. Manresa, P. F. Viladrich, R. Martin, and F. Gudiol. 1995. Resistance to penicillin and cephalosporin and mortality from severe pneumococcal pneumonia in Barcelona, Spain. N. Engl. J. Med. 333:474-480.

34. Pan, X. S., and L. M. Fisher. 1997. Targeting of DNA gyrase in Streptococcus pneumoniae by sparfloxacin: selective targeting of gyrase or topoisomerase IV by quinolones. Antimicrob. Agents Chemother. 41:471-474.

35. Piddock, L. J., M. Johnson, and S. L. Hill. 1998. Activities of new fluoroquinolones against fluoroquinolone-resistant pathogens of the lower respiratory tract. Antimicrob. Agents Chemother. 42:2956-2960.

36. Reinert, R. R., A. Al-Lahham, R. Lütticken, M. Boos, and F. J. Schmitz. 
2002. Characterization of clinical Streptococcus pneumoniae strains from Germany with decreased susceptibility to fluoroquinolones J. Antimicrob. Chemother. 49:1015-1018.

37. Rittenhouse, S., L. McCloskey, J. Broskey, N. Niconovich, C. Jakielaszek, J. Poupard, and K. Coleman. 2000. In vitro antibacterial activity of gemifloxacin and comparator compounds against common respiratory pathogens. J. Antimicrob. Chemother. 45(Suppl. S1):23-27.

38. Saravolatz, L. D., and L. Leggett. 2003. Gatifloxacin, gemifloxacin, and moxifloxacin: the role of newer fluoroquinolones. Rev. Anti-Infect. Agents 37:1210-1215.

39. Wise, R., and J. M. Andrews. 1999. The in-vitro activity and tentative breakpoint of gemifloxacin, a new fluoroquinolone. J. Antimicrob. Chemother. 44: 679-688.

40. Zeller, V., C. Janoir, M. Kitzis, L. Gutmann., and N. J. Moreau. 1997. Active efflux as a mechanism of resistance to ciprofloxacin in Streptococcus pneumoniae. Antimicrob. Agents Chemother. 41:1973-1978. 